\title{
Heterogeneous Slip Distribution Self-Similarity on a Fault Surface
}

\author{
Ya-Ting Lee ${ }^{1, *}$, Kuo-Fong Ma ${ }^{1}$, and Yin-Tung Yen ${ }^{2}$ \\ ${ }^{1}$ Department of Earth Sciences, National Central University, Taoyuan City, Taiwan, R.O.C. \\ ${ }^{2}$ Sinotech Engineering Consultants Inc., Taipei, Taiwan, R.O.C.
}

Received 5 February 2015, revised 14 October 2015, accepted 5 November 2015

\begin{abstract}
The earthquake slip distribution self-similarity is investigated in this study. We complied finite fault slip models for earthquakes in the Taiwan orogenic belt and global earthquakes to determine the slip distribution self-similarity. Forty-one earthquakes (19 Taiwan earthquakes and 22 global earthquakes) in the $\mathrm{M}_{\mathrm{w}}=4.6$ - 8.9 magnitude range were examined. The fault slip exhibited self-similar scaling between the rupture slip and area. The average area ratio $\left(R_{s}\right)$ and slip ratio $\left(R_{d}\right)$ follows a scaling of $R_{s}=10^{a-n\left(R_{d}\right)}$. Slip self-similarity implies that a fault rupture exhibits fractal behavior. The scaling exponent can be considered as a measure for the roughness degree of the slip distribution on the fault surface. This study suggests that the slip distribution for large earthquakes $\left(\mathrm{M}_{\mathrm{w}}>7.0\right)$ tends to have a more homogeneous slip. Scaling exponents can provide insight into earthquake rupture mechanics and the scaling of heterogeneous slips on the fault surface provides a basis for ground motion simulation for a finite fault for an earthquake scenario, particularly for near-fault motion.
\end{abstract}

Key words: Finite fault slip model, Self-similarity, Fractal, Heterogeneous slip

Citation: Lee, Y. T., K. F. Ma, and Y. T. Yen, 2016: Heterogeneous slip distribution self-similarity on a fault surface. Terr. Atmos. Ocean. Sci., 27, 181-193, doi: 10.3319/TAO.2015.11.05.01(T)

\section{INTRODUCTION}

Scale invariance occurs in many natural phenomena (Callan 1970; Krug 1997; Turcotte 1997; Sornette 1998; Ostojic et al. 2006; Caldarelli 2007) that show similar statistical characteristics at various scales and is a precise form of selfsimilarity. The most recognized scaling relationship for representing the self-similarity of earthquakes is that between the number of earthquakes and magnitudes reported by Gutenberg and Richter (1944). Mandelbrot (1983) proposed another concept, fractal geometry, and stated that a fractal dimension can describe the scale invariance of natural phenomena. This concept has been widely applied to describe the spatial distribution and time series of earthquakes (Turcotte 1989, 1997; Ogata and Abe 1991; Hirabayashi et al. 1992; Papadopoulos and Dedousis 1992; Koyama et al. 1995; Wang 1996; Wang and Lee 1997; Wang et al. 2014) and fault activities (cf. Okubo and Aki 1987; Lee and Schwarcz 1995). The self-similarity of earthquake slip distributions is an essential physical characteristic of earthquake kinematics and was discussed in previous studies (Beresnev and Atkinson 2002;

\footnotetext{
* Corresponding author

E-mail: shine2530@gmail.com
}

Manighetti et al. 2005, 2007; Wesnousky 2008; Klinger 2010). Wesnousky (2008) analyzed earthquake rupture traces and coseismic surface slip and obtained the scaling relationship between the slip and rupture length for strike-slip earthquakes. In addition, Manighetti et al. (2005) analyzed the scaling relationship between maximum displacement and length as well as width in 76 inverted slip models for global events. The authors showed that the overall shape of slip profiles was basically triangular and strongly asymmetric. However, the aforementioned studies focused mainly on the relationship between the amount of slip and earthquake magnitude and did not consider the scaling of the slip area partitioned in a finite fault.

The slip distribution on a finite fault is a major concern regarding the forward simulation of an earthquake scenario. In several studies the scale invariance property in earthquakes has been used for simulating the rupture process. For instance, Wang and Lee (1997) applied a fractal distribution of the breaking strengths in a spring-block model to simulate earthquakes to study the scaling relation between the earthquake frequencies and rupture length. Ide and Aochi (2005) and Aochi and Ide $(2009,2011)$ proposed a model of the wide-scale growth of dynamic rupture during an earthquake. 
Ide and Aochi (2013) used a multiscale heterogeneous model for simulating the rupture process of the Tohoku-Oki earthquake and applied numerous circular patches in the model for characterizing the heterogeneous frictional properties of the fault plane. In their analysis the area of the slip partitioned in the finite fault was simulated using several sized circular patches following a power law.

Lee et al. (2012) modeled fault rupture using a fiber bundle model which associated fibers with the asperities on a fault. The authors determined that a system at a critical transition from the nucleation to rupture phases produces a self-similarity scaling relationship between the cluster fail fibers area and the cumulative number of clusters. For determining the self-similarity properties of the slip area in a finite fault during rupture, Somerville et al. (1999), examined earthquakes in California and Murotani et al. (2008) examined earthquakes in Japan, showing that the area where slips are 1.5 times larger than the average slip is approximately $20 \%$ of the total fault rupture area. This area, defined as the area of asperity $(\mathrm{Sa})$, was considered the area most responsible for generating extreme ground motion acceleration.

Source-scaling relationships provide insight into the underlying rupture process mechanics and also provide a crucial reference for obtaining deterministic parameters for ground-motion prediction for earthquake hazard mitigation. For instance, Aagaard et al. (2010) constructed a kinematic earthquake rupture model for simulating scenarios for the fault system in Southern California. They used three-dimensional ground-motion simulation and employed geophysical constraints and empirical relationships for estimating the shaking of scenario earthquakes. The results indicated that the ground motions were sensitive to the slip distribution. In addition, Frankel (2009) applied a broadband system for constructing earthquake models with $\mathrm{M}_{\mathrm{w}}=5.5,6.5$, and 7.5 by combining deterministic synthetics for plane-layered models at low frequencies and stochastic synthetics at high frequencies. All of the aforementioned studies suggested that slip heterogeneity is an essential constraint in groundmotion simulations.

In view of the recent developments in scenario earthquake simulations for predicting ground motions toward seismic hazard assessments, the placement of the slip distribution (amount and area) within a finite fault is essential. For comprehensive datasets on earthquakes in Taiwan, Yen and Ma (2011) compiled data from 19 earthquakes in Taiwan (with 22 finite fault slip models) and 7 global events $\left(\mathrm{M}_{\mathrm{w}}>7.0\right)$ for observing the source scaling relationships of effective fault dimensions and mean slip with the seismic moment in which the source dimensions showed scale invariance. Based on these findings we further explored the relationships among the areas of slips partitioned in a finite fault. Our results suggest the fault slip exhibited self-similar scaling between the rupture slip and area. For comparing the scaling relationship of the slip distribution heterogeneity on the fault surface for Taiwanese events with that from the global dataset we included 15 additional global events listed in Mai and Beroza (2000). A comparable self-similarity feature was evident, particularly for larger events $\left(\mathrm{M}_{\mathrm{w}}>7.0\right)$. This scaling relationship between the self-similarity of the slip and slip area heterogeneity provides a reference for constructing the slip distribution of a finite-fault for an earthquake scenario toward ground-motion prediction.

\section{METHODOLOGY}

\subsection{Slip Models}

The main slip models used in this study are those developed by Yen and Ma (2011) and compiled slip models for global earthquakes developed by Mai and Beroza (2000) from a database of finite-source rupture models (Mai 2007; Mai and Thingbaijam 2014). Yen and Ma (2011) inferred the slip models for Taiwan earthquakes from the regional high-quality data recorded by the Taiwan Strong Motion Instrumentation Program (Shin and Chang 2005) and teleseismic data using the finite fault inversion technique proposed by Hartzell and Heaton (1983). The earthquake distribution and corresponding focal mechanisms are shown in Fig. 1. There are 12 dip-slip earthquakes, including the reverse-, normal-, and oblique-type events, and 7 strike-slip events. Their

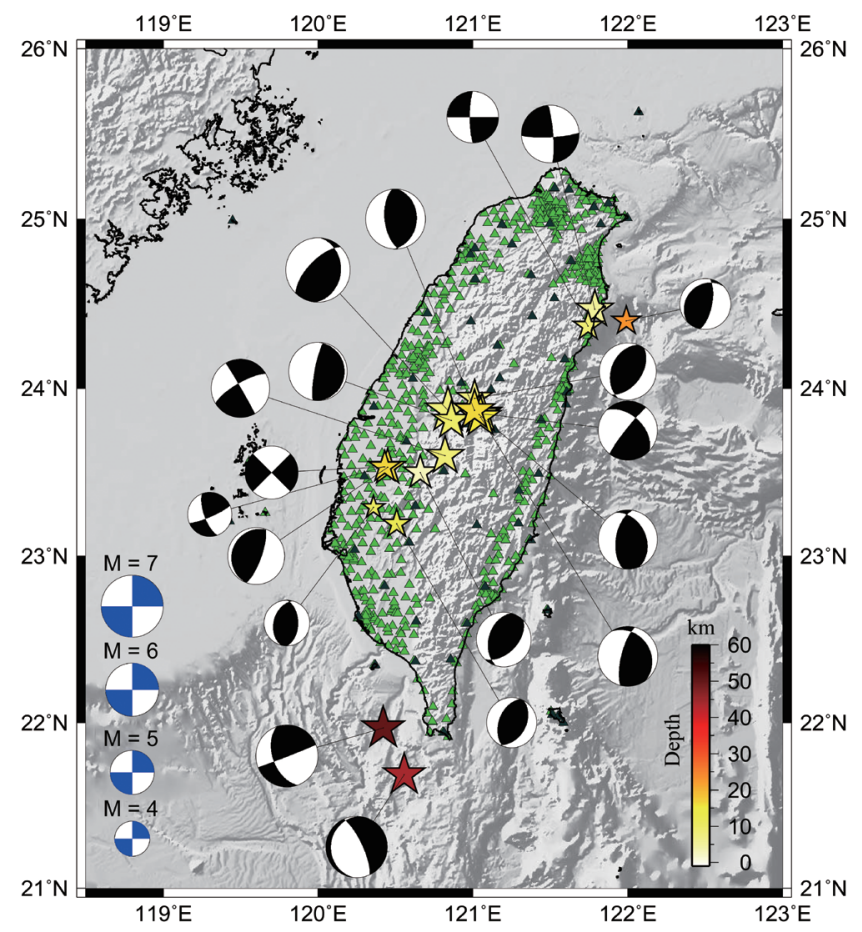

Fig. 1. Distribution of earthquakes and their corresponding focal mechanisms used in this study. Star colors represent the earthquake depth. Triangles represent the distribution of strong-motion stations of the Taiwan Strong Motion Instrumentation Program (TSMIP) (light green triangle) and Broadband Array in Taiwan for Seismology (BATS) networks (dark green triangle). (Color online only) 
magnitudes $\mathrm{M}_{\mathrm{w}}$ are 4.6 - 7.7, corresponding to seismic moments of $7.75 \times 10^{15}-4.7 \times 10^{20} \mathrm{Nm}$ (estimated using referenced slip models; Table 1). Among the 19 events, 14 events were located in the fold-and-thrust belt of the Taiwan orogenic collision zone. For global events, according to Yen and Ma (2011), 7 global event slip models were used for compensating for the lack of larger events $\left(\mathrm{M}_{\mathrm{w}}>7.0\right)$ in the Taiwan region.

For comparison with the aforementioned slip models mainly for Taiwanese events, we considered additional slip models for global events. Several slip models of global earthquakes were compiled and can be viewed at: http:// www.seismo.ethz.ch/static/srcmod/Homepage.html. The Web site includes several new source models, updates for existing source model entries, and appended additional information (Mai 2007, database of finite-source rupture models). In addition, the Web site displays finite-source rupture models that describe the spatiotemporal evolution of earthquake rupture through the modeling or inversion of seismic and geodetic data. The Web site contains 152 rupture models for 80 earthquakes $\left(\mathrm{M}_{\mathrm{w}}=4.1-8.9\right)$ in various tectonic regimes. Mai and Beroza (2000) listed 31 published slip models for 18 events that are the most accurate estimates of true fault dimensions as noted in their compilation. These slip models are typically derived from the finite fault inversion of low-pass-filtered strong-motion recordings (Archuleta 1984; Beroza and Spudich 1988). There are 10 dip-slip and 8 strike-slip events in the database, with magnitudes $\mathrm{M}_{\mathrm{w}}$ being $5.9-8.1$, corresponding to seismic moments of $2.2 \times 10^{17}-1.2 \times 10^{21} \mathrm{Nm}$ (estimated using referenced slip models; Table 2). Since three events overlapped with the previous databases of Yen and Ma (2011), 15 additional global earthquakes, with their corresponding 28 slip models, were included in addition to the slip models of Yen and Ma (2011) for the analysis and comparison. The number of earthquakes in study is 41 , including 19 Taiwan earthquakes and 7 global events, from Yen and Ma (2011) and 15 global earthquakes from Mai and Beroza (2000), with magnitudes $\mathrm{M}_{\mathrm{w}}$ ranging from 4.6 - 8.9 with various fault types.

\subsection{Determination of Source Dimensions and Scaling Parameters}

For determining effective source dimensions, the spatial autocorrelation scheme developed by Mai and Beroza (2000) was adopted for defining the effective fault dimensions of length and width of the slip models. In addition, a spatial slip function along the strike direction, where the slips on each subfault along the dip direction are summed, was considered. Similarly, a spatial slip function along the dip was obtained by summing the slip on each subfault along the strike direction. The spatial slip function was defined as $f(x)$ in Eq. (1). Furthermore, an autocorrelation method was used for estimating the effective dimensions of two spatial functions in the strike and dip directions. An example of an estimate of the effective dimensions using the slip model proposed by Ma et al. (2001) for the $1999 \mathrm{M}_{\mathrm{w}}$ 7.6 Chi-Chi, Taiwan earthquake is shown in Fig. 2. The effective dimensions are defined using the autocorrelation slip function divided by the maximum value of autocorrelation function at zero lag as follows:

$W^{A C F}=\frac{\int_{-\infty}^{\infty}\left(f^{*} f\right) d x}{\left.f^{*} f\right|_{x=0}}$

where $W^{A C F}$ denotes the effective dimension of $L_{e}$ or $W_{e}$, where $L_{e}$ and $W_{e}$ are the effective length and width along the strike and dip directions, respectively.

The mean slip is defined using the relationship between seismic moment and source dimensions as follows:

$M_{0}=\mu L_{e} W_{e} d_{m}$

where $\mu$ is the rigidity of crustal rock, and $d_{m}$ is the average effective slip or the mean slip. The derived effective source parameters, i.e., $L_{e}, W_{e}$, and $d_{m}$ for all events obtained through this analysis are listed in Table 1 . We also consider the fault area as $A_{e}$, which denotes the effective area of $L_{e}$ $\times W_{e}$. For a scaling analysis of the amount of slip and slip area, the following parameters were defined. The area of asperity, $S a$, which is the area where the slips are 1.5 times larger than the mean slip, $d_{m}$, as definition of Somerville et al. (1999). For determining the area of the slip partitioned in a finite fault, $R_{d}$ and $R_{s}$, are introduced. $R_{d}$ and $R_{s}$ are the normalized slip and slip area, respectively, of the compiled slip models. $R_{d}$ is defined as the ratio of $d$ to $d_{m}$, i.e., $d / d_{m}$, where $d$ is the slip within the finite-fault and $d_{m}$ is the mean slip; $R_{s}$ is defined as the ratio of $A$ to $A_{e}$, i.e., $A / A_{e}$, where $A$ is the slipped area with a slip amount larger than $R_{d}$ and $A_{e}$ is the effective ruptured area. Here, $R_{d}$ was considered 0.25 4.0 for every 0.25 increment, referring to the slip area where slips are $>(0.25-4.0) d_{m}$ for every $0.25 d_{m}$. As previously mentioned the slip models were inverted mainly from the strong motion data of individual studies (Tables 1 and 2); therefore, the resolution of each inverted slip distribution might vary. However, using the normalization parameters as $R_{d}$ and $R_{s}$ for each slip model minimizes the influence of model resolution on our scaling analysis.

\section{RESULTS}

\subsection{Scaling Relationship of Asperity to Magnitude}

To examine the relationship between $S a$ and $\mathrm{M}_{\mathrm{w}}$, the asperity to magnitude scaling relationship is illustrated using the slip models in Fig. 3. Two scaling relationship regressions, $S a=1.58 \mathrm{M}_{\mathrm{w}}-(8.29 \pm 0.33)$ for earthquakes with $\mathrm{M}_{\mathrm{w}}=4.5-7.0$ and $S a=0.83 \mathrm{M}_{\mathrm{w}}-(3.77 \pm 0.36)$ for 


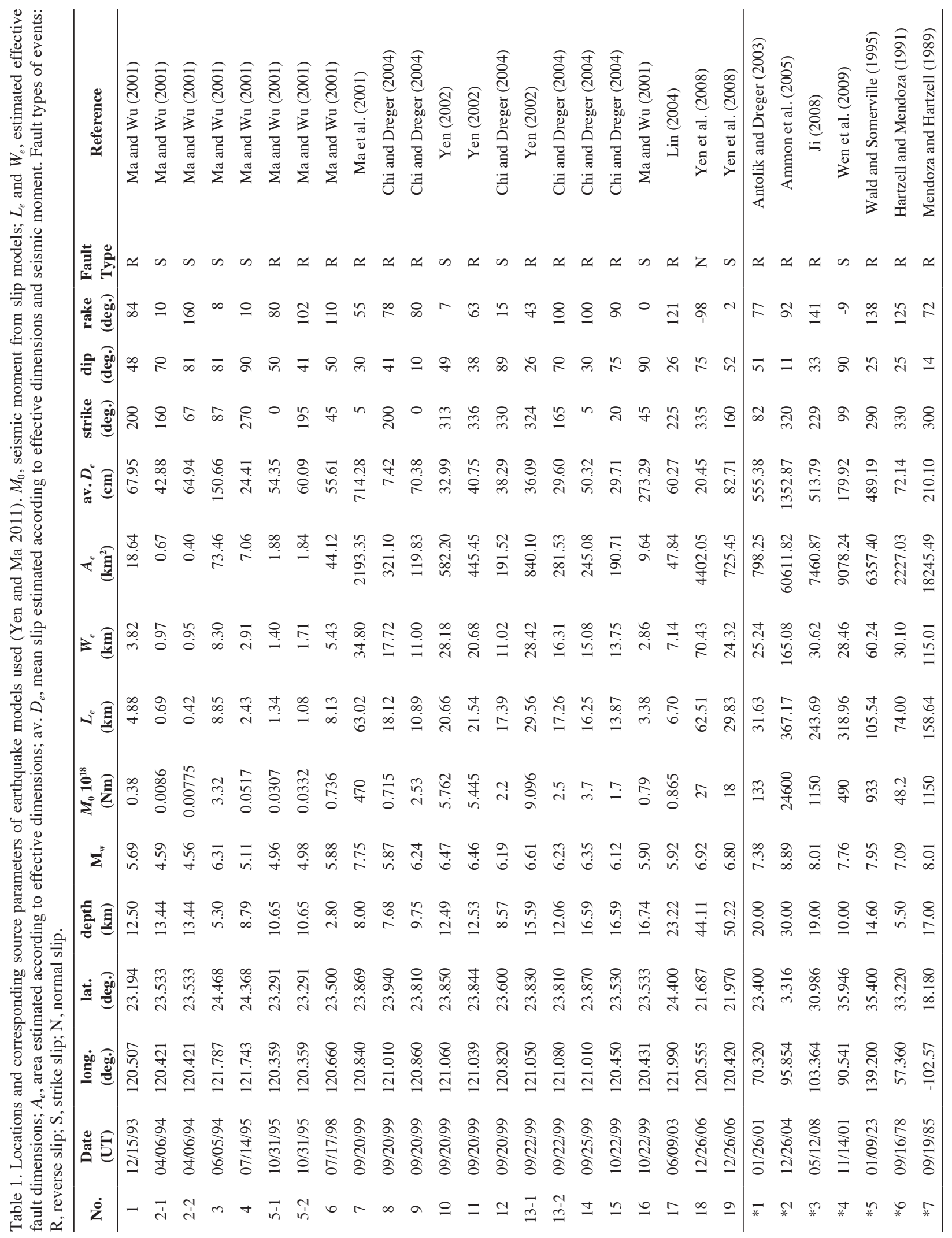




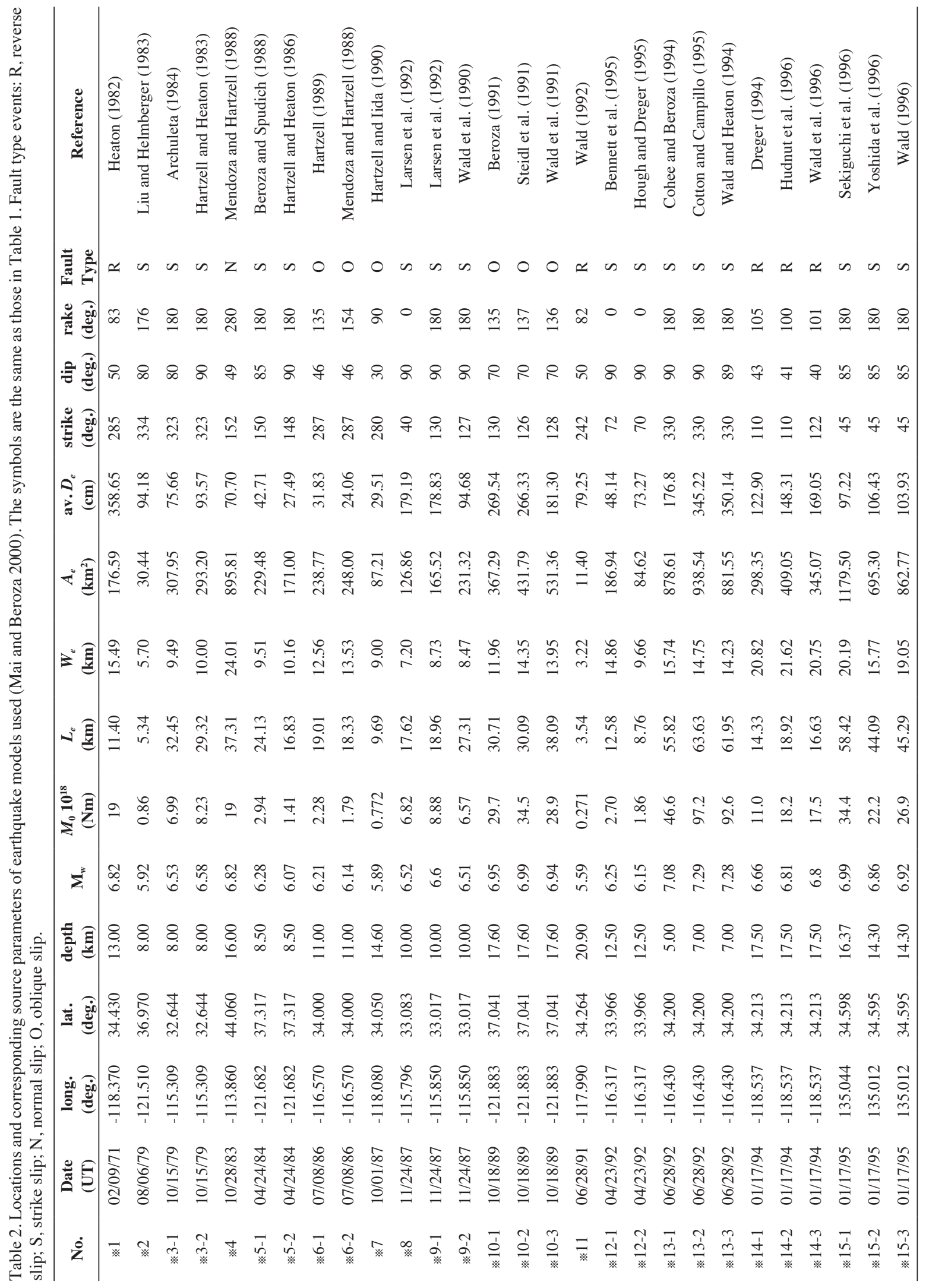




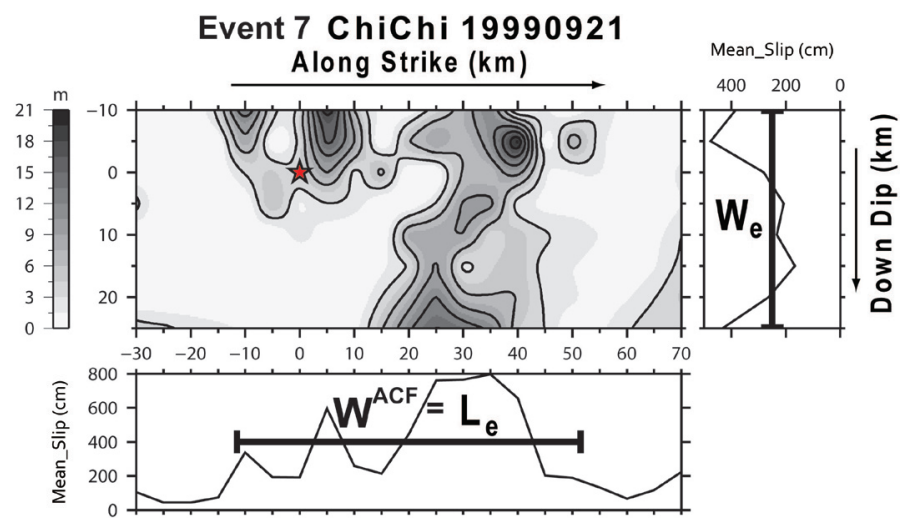

Fig. 2. Illustration of how effectively fault length and width were estimated using the slip model of the 1999 Chi-Chi earthquake derived from Ma et al. (2001). Two slip functions were obtained by summing the slip of each subfault along the down-dip and strike directions and were used for obtaining the effective fault width $\left(W_{e}\right)$ and length $\left(L_{e}\right)$ (Yen and Ma 2011). (Color online only)

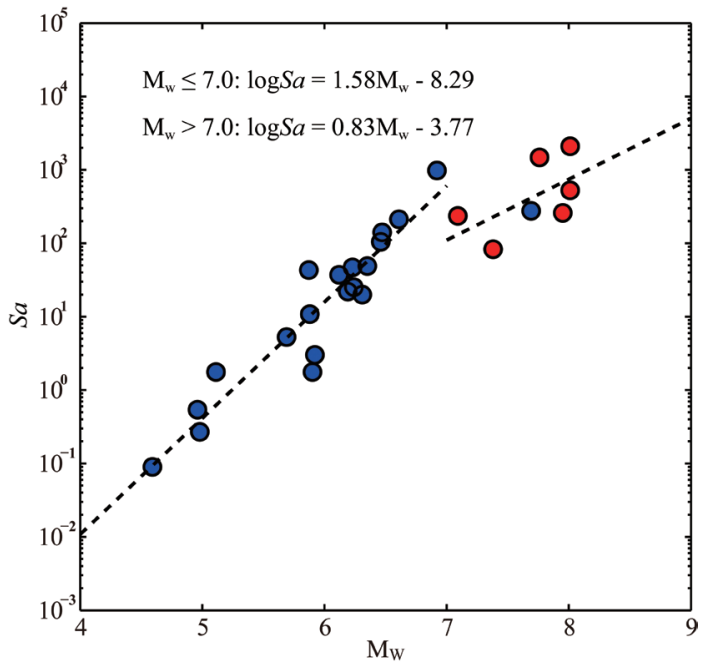

Fig. 3. Scaling relationships of the asperity area (at $R_{d}>1.5$ ) to the moment magnitude of the finite fault slip models developed by Yen and Ma (2011). The blue dots denote Taiwan earthquakes and the red dots denote global earthquakes. The black lines show the best fitting for the earthquakes with $\mathrm{M}_{\mathrm{w}}=4.5-7.0$ and those with $\mathrm{M}_{\mathrm{w}}>7.0$. The black dashed lines show the standard deviations of the asperity area. (Color online only)

earthquakes with $\mathrm{M}_{\mathrm{w}}>7.0$, were performed. The $S a$ value is approximately $20 \%$ of $A_{e}$, which is similar to those calculated by Somerville et al. (1999) and Murotani et al. (2008) for earthquakes in California and Japan, respectively (Fig. 4). Figure 5 shows the scaling relationship for asperity to magnitude by considering additional global events from Taiwanese events using a total of 41 events. Two scaling relationship regressions, $S a=1.07 \mathrm{M}_{\mathrm{w}}-(5.44 \pm 0.49)$ for earthquakes with $\mathrm{M}_{\mathrm{w}}=4.5-7.0$ and $S a=0.82 \mathrm{M}_{\mathrm{w}}-(3.73 \pm 0.35)$ for earthquakes with $\mathrm{M}_{\mathrm{w}}>7.0$, were conducted.

\subsection{Slip Area to Slip Scaling in a Finite Fault}

According to the definitions of $R_{d}$ and $R_{s}$, we obtained the slip area as a function of the slip from the compiled slip models. Figure 6 shows the plot of $\log \left(R_{s}\right)$ versus $R_{d}$ for the fault slip models provided by Yen and Ma (2011) (see Table1). The results show a self-similar scaling of slip values, with $R_{s}=10^{a-n\left(R_{d}\right)}$. For finite fault models of moderate magnitude $\left(\mathrm{M}_{\mathrm{w}}=4.5-7.0\right)$, the relationship between $R_{s}$ and $R_{d}$ shows two scaling exponents $(n), 0.46$ and 0.32 , for $R_{d}$ ranges of $0<R_{d} \leq 2.0$ and $2.0<R_{d} \leq 4.0$, respectively (Fig. 6). However, as also shown in Fig. 6, when only the events with $\mathrm{M}_{\mathrm{w}}>7.0$ are considered, the scaling relationship for $R_{s}$ as a function of $R_{d}$ follows only one scaling relation as $\log R_{s}=-0.69 R_{d}+(0.09 \pm 0.16)$.

For considering additional global events (Mai and Beroza 2000), the relationship between $R_{s}$ and $R_{d}$ for the compiled 43 finite fault models with $\mathrm{M}_{\mathrm{w}}=4.5-7.0$ and 14 finite fault models with $\mathrm{M}_{\mathrm{w}}>7.0$ is shown in Fig. 7. For $\mathrm{M}_{\mathrm{w}}$ $=4.5-7.0$, the scaling exponents $(n)$ are 0.66 and 0.23 for $R_{d}$ ranges of $0<R_{d} \leq 2.0$ and $2.0<R_{d} \leq 4.0$, respectively. 


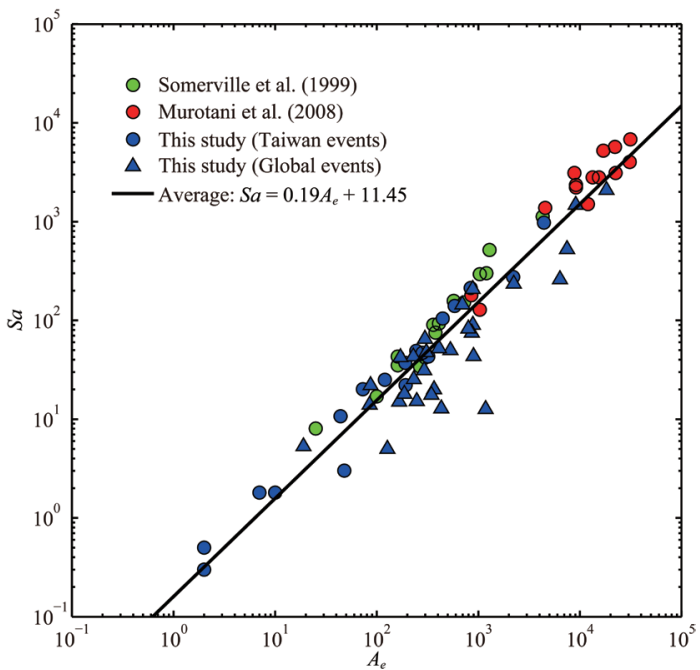

Fig. 4. Asperity area $(\mathrm{Sa})$ versus rupture area $\left(A_{e}\right)$. Green dots represent California earthquakes (Somerville et al. 1999). Red dots represent Japan earthquakes (Murotani et al. 2008). Blue dots represent the Taiwan earthquakes (Yen and Ma 2011) used. Blue triangles represent the global earthquake models used: seven from Yen and Ma (2011) and 28 from Mai and Beroza (2000). The black line represents the regression line for all datasets, and the black dashed lines show the standard deviation of $\mathrm{Sa}$ for all datasets. (Color online only)

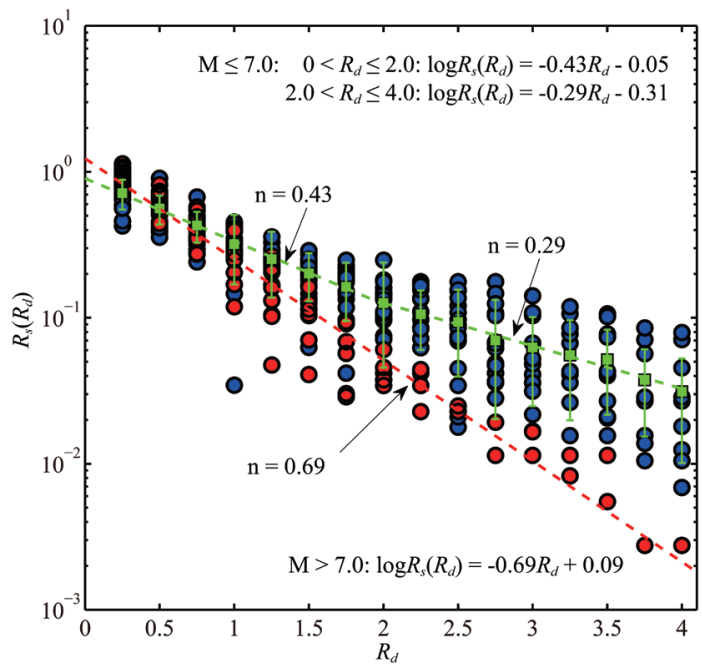

Fig. 6. Scaling relationships of $R_{s}$ to $R_{d} . R_{d}$ is the ratio of the slip to the mean slip. $R_{s}$ is the ratio of the fault area to the effective area $\left(A_{e}\right)$. Blue dots denote earthquakes with $\mathrm{M}_{\mathrm{w}}=4.5$ - 7.0, while red dots denote earthquakes with $\mathrm{M}_{\mathrm{w}}>7.0$. Grey squares show the mean of $\log R_{s}$ of the earthquakes with $\mathrm{M}_{\mathrm{w}}=4.5-7.0$ for different $R_{d}$ values. The black lines show the best fitting between the average of $R_{s}\left(d>R_{d} \times d_{m}\right)$ and $R_{d}$ for $R_{d}$ ranges of $0<R_{d} \leq 2.0$ and $2.0<R_{d}$ $\leq 4.0$ and earthquakes with $\mathrm{M}_{\mathrm{w}}=4.5-7.0$. The red line shows the best fitting of $R_{s}$ and $R_{d}$ for earthquakes with $\mathrm{M}_{\mathrm{w}}>7.0$. The black dashed and red dashed lines represent the standard deviations of $R_{s}$ for earthquakes with $\mathrm{M}_{\mathrm{w}}=4.5-7.0$ and those with $\mathrm{M}_{\mathrm{w}}>7.0$, respectively. (Color online only)

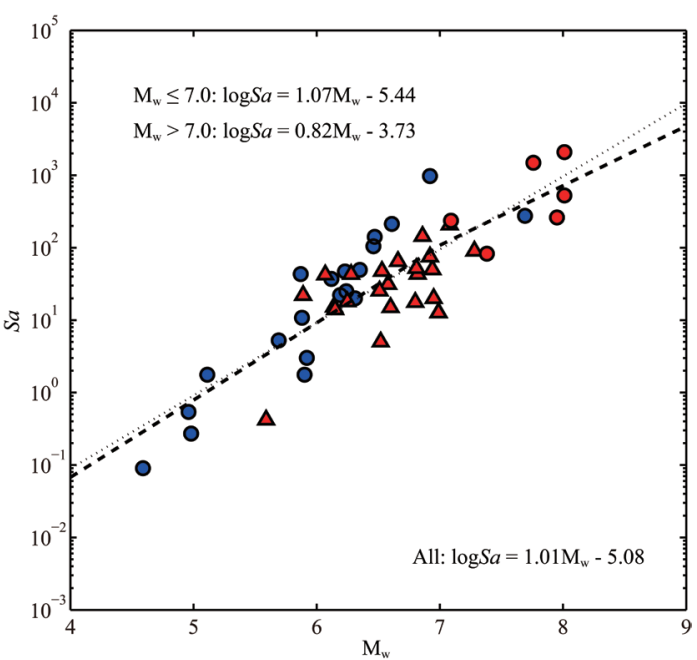

Fig. 5. Scaling relationships of the asperity area (at $R_{d}>1.5$ ) to the moment magnitude. The symbols are the same as those in Fig. 3. Additional finite fault slip models of global earthquakes from Mai and Beroza (2000) are shown using triangles. The black lines show the two best fittings for earthquakes with $\mathrm{M}_{\mathrm{w}}=4.5-7.0$ and those with $\mathrm{M}_{\mathrm{w}}>7.0$. The red dot-dashed line shows the best fitting for the entire dataset. The black dashed lines show the standard deviations of the asperity area with $\mathrm{M}_{\mathrm{w}}=4.5-7.0$ and those with $\mathrm{M}_{\mathrm{w}}>7.0$. (Color online only)

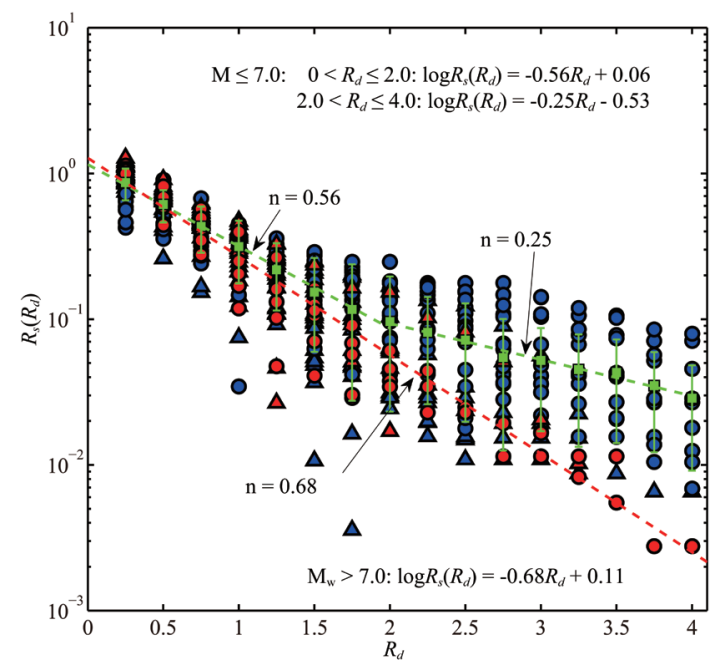

Fig. 7. Scaling relationships of $R_{s}$ to $R_{d}$. The symbols are the same as those in Fig. 6. Additional finite fault slip models of global earthquakes obtained from Mai and Beroza (2000) are shown using triangles. (Color online only) 
In addition, the scaling relationship between $R_{s}$ and $R_{d}$ for large earthquakes with $\mathrm{M}_{\mathrm{w}}>7.0$ follows a scaling relation of $\log R_{s}=-0.68 R_{d}+(0.11 \pm 0.21)$, similar to the results of the fault slip models shown in Table 1 .

To disaggregate the results among events the value of $R_{s}$ in terms of $\mathrm{M}_{\mathrm{w}}$ for different $R_{d}$ values $\left(R_{d}=0.25-4.0\right)$ is presented in Fig. 8. In addition, the variance $(\Delta \sigma)$ of $R_{s}$ for different $R_{d}$ values was also calculated. The result indicates that the average $R_{s}$ value decreases with increasing $R_{d}$. Furthermore, the $\Delta \sigma$ of $R_{s}$ is approximately $<0.1$ when $R_{d}$ is $>1.0$, and the $\Delta \sigma$ of $R_{s}$ decreases with $R_{d}$. The ratio of slipped area $\left(R_{s}\right)$ with lower bound of $R_{d}$ (e.g., $R_{d}=0.25$ and 0.5 ) is lower in Taiwan earthquakes than that in global earthquakes. Except for the lower bound of $R_{d}$, most of the earthquakes exhibited a similar effective area ratio with a slip larger than $R_{d}$ times the mean slip $R_{\mathrm{s}}\left(d>R_{d} \times d_{m}\right)$. The similar ratio of the effective area $R_{\mathrm{s}}\left(d>R_{d} \times d_{m}\right)$ of the slip models is a feature of the scale invariance of the slip distribution.

\section{DISCUSSION}

Comparing the $S a$ values for Taiwanese and global earthquakes, the values for Taiwanese events are generally larger for $\mathrm{M}_{\mathrm{w}}=4.5-7.0$ as the scaling slope for these events in Fig. 3 is larger than that in Fig. 5. However, similar trends are evident for earthquakes with $\mathrm{M}_{\mathrm{w}}>7.0$ (Figs. 3 and 5). The differences in this might due to the differences in stress drops, which were not taken into account in this scaling analysis. As in the studies of Yen and Ma (2011), several moderate events in the Taiwan fold-and-thrust belt region exhibit large stress drops. These events with large stress drops might yield larger $S a$ values for Taiwanese earthquakes than for
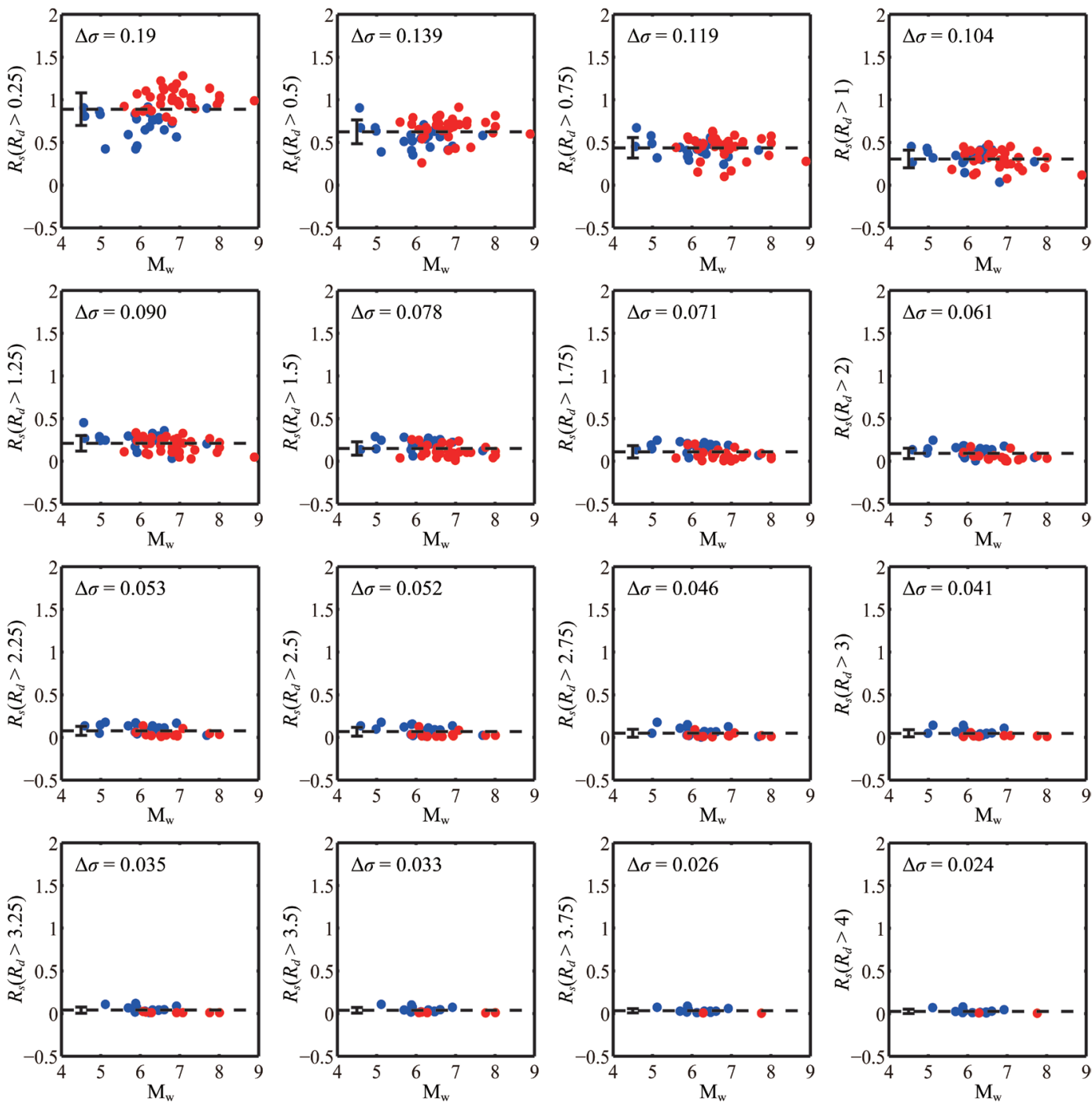

Fig. 8. The variance of $R_{s}$ with magnitude for different $R_{d}$ values. $R_{d}$ is $d / d_{m}$, the ratio of the slip, $d$, to the mean slip $\left(d_{m}\right)$. $R_{s}$ is $A / A_{e}$, the ratio of the fault area $(A)$, where slip $d>R_{d} \times d_{m}$, to the effective area $\left(A_{e}\right)$. The effective area and slip were determined according to the normalized autocorrelation of slip length with slip width. Dashed lines represent the average $R_{s}$ values. Blue dots denote Taiwan earthquakes, while red dots denote global earthquakes. (Color online only) 
global ones. However, for larger earthquakes $M_{w}>7.0$, the variation in stress drop become insignificant, which, thus, yields similar scaling in the whole dataset.

The slip area to slip scaling gives the area of slips partitioned in a finite fault. Our study shows that the scaling relationship follows the relation of $R_{s}=10^{a-n\left(R_{d}\right)}$. The scaling exponent $n$ represents the degree of slip heterogeneity, where the higher $n$ is the smoother the slip distribution. The earthquakes with moderate magnitudes exhibit more significant slip self-similarity for a slip less than twice the mean slip $\left(d \leq 2.0 d_{m}\right)$ for less variance compared to the slip larger than twice the mean slip $\left(d>2.0 d_{m}\right)$. The difference in $n$ for $d \leq 2.0 d_{m}$ and $d>2.0 d_{m}$ suggests that the region with larger slip is more isolated for the area with larger slips $\left(d>2.0 d_{m}\right)$. These features were found not only in Taiwanese (Fig. 6), but also in the global dataset (Fig. 7) of Mai and Beroza (2000). However, if we considered only the earthquakes with magnitudes greater than 7.0, as shown in Figs. 6 and 7 for Taiwanese and the global dataset, the selfsimilarity becomes invariant throughout the whole range of slip ratios. Although Manighetti et al. (2005) suggested that the maximum displacement on the fault is less than twice the average slip. The slip model we examined did reveal the slips, which are larger than twice the average slip. From the adopted global dataset we note that 10 out of the 31 slip models present a slip with $d>2.0 d_{m}$, including multiple models from a common event.

Slip self-similarity implies that fault rupture is a fractal behavior with the fractal dimension of $n$. The fractal character of slip distribution is to describe the variety of fault structures that are irregular with roughness or heterogeneity. The rupture process is generated by the stress field under the heterogeneity of the fault surface. A fractal distribution of fault surface roughness has been shown in the field observations (Aviles et al. 1987; Okubo and Aki 1987) and laboratory experiments (Brown and Scholz 1985; Power et al. 1987). Wang and Lee (1997) suggested that the fractal geometry of a fault might have a strong relationship with the fractal heterogeneous distribution of the breaking strengths over the fault. Our study shows different scaling exponents $(n)$ between larger earthquakes of $\mathrm{M}_{\mathrm{w}}>7.0(n \approx 0.7)$ and moderate earthquakes of $\mathrm{M}_{\mathrm{w}}=4.5-7.0(n<0.7)$, suggesting the slip distribution for larger magnitude earthquakes tend to be more homogenous. The different scaling relationships could be attributed to the difference in rupture dynamics. The more heterogeneous the slip distributions for moderate earthquakes might be related to the variations in breaking strength over the fault plane as suggested by Wang and Lee (1997); while the more homogenous slip distribution for larger earthquakes $\left(\mathrm{M}_{\mathrm{w}}>7.0\right)$ might suggest more significant influence from dynamic rupture process, e.g., thermal pressurization or melting (Kanamori and Brodsky 2004; Ma et al. 2006).

Discrepancies in source scaling for earthquakes have been observed and discussed previously (Shimazaki 1986;
Wang 1997; Wang and Ou 1998; Hanks and Bakun 2002, 2008; Manighetti et al. 2007; Shaw and Wesnousky 2008). Wang and Ou (1998) analyzed the scaling relation among seismic moment, average displacement, rupture width and rupture length of earthquake fault models. Their results showed that rupture width is independent of rupture length for large earthquakes. Mai and Beroza (2000) analyzed source dimension scaling and observed that scale invariance breaks down for large strike-slip events. They suggested that the breakdown is caused by rupture width saturation. In addition, Yen and Ma (2011) observed that the bilinear feature of magnitude-area scaling appears at a ruptured area of approximately $1000 \mathrm{~km}^{2}$ for a seismogenic thickness of $35 \mathrm{~km}$ in Taiwan. They suggested that the seismogenic thickness controls the evolution of earthquake scaling in fault geometry. Comparatively, in GutenbergRichter scaling, several authors observed a breakdown in scaling for large earthquakes (Rundle 1989; Pacheco et al. 1992; Wu et al. 2013). Rundle (1989) suggested that a transition of the $b$ value (the scaling exponent of magnitude and frequency) from $1-1.5$ is caused by the approximately equidimensional (width $\approx$ length) for smaller events, whereas larger earthquakes (long, shallow strike-slip earthquakes) have considerably greater lengths than depths. Furthermore, Manighetti et al. (2007) analyzed the relationship between displacements and rupture lengths and discovered a scaling break between moderate and large earthquakes. The authors suggested that the scaling break results from the multipleevent rupture process of large earthquakes (Klinger 2010). The behavior in scaling breaking between $\mathrm{M}_{\mathrm{w}}>7.0$ and $\mathrm{M}_{\mathrm{w}}=4.5-7.0$ observed in this study is similar to that in those aforementioned studies. However, in our study, we indicated further that the fractal heterogeneous distribution also exhibits the breakdown, which suggests a difference in rupture dynamics between moderate and large earthquakes. Although the earthquake rupture dynamics are still difficult to model specifically, the difference in the fractal heterogeneity could be empirically presented by $R_{s}=10^{a-n\left(R_{d}\right)}$ as shown in this study.

\section{CONCLUSIONS}

This study compiled published finite fault models (19 of Taiwan earthquakes and 22 of global earthquakes) for analyzing the scaling self-similarity of the slip distribution in earthquakes. A scaling relationship between the fault slip and area was examined. Our results suggest a self-similarity in the heterogeneity in slip distribution over the fault. The self-similar scaling exponent indicates the degree of fractal dimension in the fault slip system. The spatial slip distribution for large earthquakes $\left(\mathrm{M}_{\mathrm{w}}>7.0\right)$ follows a scaling of $\log R_{s}=-0.68 R_{d}+(0.11 \pm 0.21)$, and tends to have a more homogeneous slip distribution compared to the moderate events. In addition, a breaking in the asperity source scaling 
between $M_{w}>7.0$ and $M_{w}=4.5-7.0$ was found. The difference in scaling behavior might be attributed to the rupture dynamics.

In addition to the physical implication of earthquake dynamics from the self-similarity of heterogeneous slip distribution, the scaling relationship for the slip partition in a finite-fault derived in this study provides an important basis for ground-motion prediction, which is particularly crucial in assessing seismic hazards and simulating earthquake scenarios. Our investigations over the databases for Taiwan and Global earthquake events, individually, give the comparison on the validation of the scaling relations for the Taiwan region and its general features for the global dataset. For the comprehensive seismic dataset of Taiwan, our study, thus, also provides an essential reference for global communities involved in the ground-motion prediction of earthquake scenarios. This ground motion prediction is essential for establishing the next-generation attenuation relationships, especially for the near-fault motions, and, thus, in probabilistic seismic hazard assessment.

Acknowledgements The authors are grateful for research support from both the Ministry of Science and Technology (MOST) and the Department of Earth Sciences, National Central University, Taiwan, ROC. Thanks to Central Weather Bureau Seismological Network for providing high-quality seismic data. This research was supported by funded through MOST, with project grant number MOST 103-2116-M-008008-MY3 and the Taiwan Earthquake Research Center(TEC) funded through MOST, formerly National Science Council (NSC), with Taiwan Earthquake Model (TEM) project grant number MOST 105-2119-M-006-016. The TEC contribution number for this article is 00200 .

\section{REFERENCES}

Aagaard, B. T., R. W. Graves, D. P. Schwartz, D. A. Ponce, and R. W. Graymer, 2010: Ground-motion modeling of Hayward fault scenario earthquakes, Part I: Construction of the suite of scenarios. Bull. Seismol. Soc. Am., 100, 2927-2944, doi: 10.1785/0120090324. [Link]

Ammon, C. J., C. Ji, H. K. Thio, D. Robinson, S. Ni, V. Hjorleifsdottir, H. Kanamori, T. Lay, S. Das, D. Helmberger, G. Ichinose, J. Polet, and D. Wald, 2005: Rupture process of the 2004 Sumatra-Andaman earthquake. Science, 308, 1133-1139, doi: 10.1126/science.1112260. [Link]

Antolik, M. and D. S. Dreger, 2003: Rupture process of the 26 January $2001 M_{\mathrm{w}} 7.6 \mathrm{Bhuj}$, India, earthquake from teleseismic broadband data. Bull. Seismol. Soc. Am., 93, 1235-1248, doi: 10.1785/0120020142. [Link]

Aochi, H. and S. Ide, 2009: Complexity in earthquake sequences controlled by multiscale heterogeneity in fault fracture energy. J. Geophys. Res., 114, B03305, doi:
10.1029/2008JB006034. [Link]

Aochi, H. and S. Ide, 2011: Conceptual multi-scale dynamic rupture model for the 2011 off the Pacific coast of Tohoku earthquake. Earth Planets Space, 63, 761-765, doi: 10.5047/eps.2011.05.008. [Link]

Archuleta, R. J., 1984: A faulting model for the $1979 \mathrm{Im}$ perial Valley earthquake. J. Geophys. Res., 89, 45594585, doi: 10.1029/JB089iB06p04559. [Link]

Aviles, C. A., C. H. Scholz, and J. Boatwright, 1987: Fractal analysis applied to characteristic segments of the San Andreas Fault. J. Geophys. Res., 92, 331-344, doi: 10.1029/JB092iB01p00331. [Link]

Bennett, R. A., R. E. Reilinger, W. Rodi, Y. Li, M. N. Toksöz, and K. Hudnut, 1995: Coseismic fault slip associated with the $1992 M_{\mathrm{w}}$ 6.1 Joshua Tree, California, earthquake: Implications for the Joshua Tree-Landers earthquake sequence. J. Geophys. Res., 100, 64436461, doi: 10.1029/94JB02944. [Link]

Beresnev, I. A. and G. M. Atkinson, 2002: Source parameters of earthquakes in eastern and western North America based on finite-fault modeling. Bull. Seismol. Soc. Am., 92, 695-710, doi: 10.1785/0120010101. [Link]

Beroza, G. C., 1991: Near-source modeling of the Loma Prieta earthquake: Evidence for heterogeneous slip and implications for earthquake hazard. Bull. Seismol. Soc. Am., 81, 1603-1621.

Beroza, G. C. and P. Spudich, 1988: Linearized inversion for fault rupture behavior: Application to the 1984 Morgan Hill, California, earthquake. J. Geophys. Res., 93, 6275-6296, doi: 10.1029/JB093iB06p06275. [Link]

Brown, S. R. and C. H. Scholz, 1985: Broad bandwidth study of the topography of natural rock surface. J. Geophys. Res., 90, 12575-12582, doi: 10.1029/ JB090iB14p12575. [Link]

Caldarelli, G., 2007: Scale-Free Networks: Complex Webs in Nature and Technology, Oxford Finance Series, Oxford University Press, $336 \mathrm{pp}$.

Callan, C. G., Jr., 1970: Broken scale invariance in scalar field theory. Phys. Rev. D, 2, 1541-1547, doi: 10.1103/ PhysRevD.2.1541. [Link]

Chi, W. C. and D. Dreger, 2004: Crustal deformation in Taiwan: Results from finite source inversions of six $M_{w}>5.8$ Chi-Chi aftershocks. J. Geophys. Res., 109, B07305, doi: 10.1029/2003JB002606. [Link]

Cohee, B. P. and G. C. Beroza, 1994: Slip distribution of the 1992 Landers earthquake and its implications for earthquake source mechanics. Bull. Seismol. Soc. Am., 84, 692-712.

Cotton, F. and M. Campillo, 1995: Frequency domain inversion of strong motions: Application to the 1992 Landers earthquake. J. Geophys. Res., 100, 3961-3975, doi: 10.1029/94JB02121. [Link]

Dreger, D. S., 1994: Empirical Green's function study of the January 17, 1994 Northridge, California earthquake. 
Geophys. Res. Lett., 21, 2633-2636, doi: 10.1029/94GL02661. [Link]

Frankel, A., 2009: A constant stress-drop model for producing broadband synthetic seismograms: Comparison with the Next Generation Attenuation relations. Bull. Seismol. Soc. Am., 99, 664-680, doi: 10.1785/0120080079. [Link]

Gutenberg, B. and C. F. Richter, 1944: Frequency of earthquakes in California. Bull. Seismol. Soc. Am., 34, 185188.

Hanks, T. C. and W. H. Bakun, 2002: A bilinear sourcescaling model for M-log A observations of continental earthquakes. Bull. Seismol. Soc. Am., 92, 1841-1846, doi: 10.1785/0120010148. [Link]

Hanks, T. C. and W. H. Bakun, 2008: M-logA observations for recent large earthquakes. Bull. Seismol. Soc. Am., 98, 490-494, doi: 10.1785/0120070174. [Link]

Hartzell, S. H., 1989: Comparison of seismic waveform inversion results for the rupture history of a finite fault: Application to the 1986 North Palm Springs, California, earthquake. J. Geophys. Res., 94, 7515-7534, doi: 10.1029/JB094iB06p07515. [Link]

Hartzell, S. H. and T. H. Heaton, 1983: Inversion of strong ground motion and teleseismic waveform data for the fault rupture history of the 1979 Imperial Valley, California, earthquake. Bull. Seismol. Soc. Am., 73, 15531583.

Hartzell, S. H. and T. H. Heaton, 1986: Rupture history of the 1984 Morgan Hill, California, earthquake from the inversion of strong motion records. Bull. Seismol. Soc. Am., 76, 649-674.

Hartzell, S. H. and M. Iida, 1990: Source complexity of the 1987 Whittier Narrows, California, earthquake from the inversion of strong motion records. J. Geophys. Res., 95, 12475-12485, doi: 10.1029/JB095iB08p12475. [Link]

Hartzell, S. H. and C. Mendoza, 1991: Application of an iterative least-squares waveform inversion of strongmotion and teleseismic records to the 1978 Tabas, Iran, earthquake. Bull. Seismol. Soc. Am., 81, 305-331.

Heaton, T. H., 1982: The 1971 San Fernando earthquake: A double event? Bull. Seismol. Soc. Am., 72, 2037-2062.

Hirabayashi, T., K. Ito, and T. Yoshii, 1992: Multifractal analysis of earthquakes. Pure Appl. Geophys., 138, 591-610, doi: 10.1007/BF00876340. [Link]

Hough, S. E. and D. S. Dreger, 1995: Source parameters of the 23 April 1992 M 6.1 Joshua Tree, California, earthquake and its aftershocks: Empirical Green's function analysis of GEOS and TERRAscope data. Bull. Seismol.Soc. Am., 85, 1576-1590.

Hudnut, K. W., Z. Shen, M. Murray, S. McClusky, R. King, T. Herring, B. Hager, Y. Feng, P. Fang, A. Donnellan, and Y. Bock, 1996: Co-seismic displacements of the 1994 Northridge, California, earthquake. Bull. Seis- mol. Soc. Am., 86, S19-S36.

Ide, S. and H. Aochi, 2005: Earthquakes as multiscale dynamic ruptures with heterogeneous fracture surface energy. J. Geophys. Res., 110, B11303, doi: 10.1029/2004JB003591. [Link]

Ide, S. and H. Aochi, 2013: Historical seismicity and dynamic rupture process of the 2011 Tohoku-Oki earthquake. Tectonophysics, 600, 1-13, doi: 10.1016/j.tecto.2012.10.018. [Link]

Ji, C., 2008: Preliminary result of the May 12, $2008 \mathrm{Mw}$ 7.97 Sichuan earthquake. Available at http://www. geol.ucsb.edu/faculty/ji/big_earthquakes/2008/05/12/ ShiChuan.html (last accessed 22 February 2010).

Kanamori, H. and E. E. Brodsky, 2004: The physics of earthquakes. Rep. Progr. Phys., 67, 1429-1496, doi: 10.1088/0034-4885/67/8/R03. [Link]

Klinger, Y., 2010: Relation between continental strikeslip earthquake segmentation and thickness of the crust. J. Geophys. Res., 115, B07306, doi: 10.1029/2009JB006550. [Link]

Koyama, J., S. X. Zang, and T. Ouchi, 1995: Mathematical modeling and stochastic scaling of complex earthquake activity. In: Koyama, J. and D. Feng (Eds.), Advances in Mathematical Seismology, Seismological Press, Beijing, 165-180.

Krug, J., 1997: Origins of scale invariance in growth processes. Adv. Phys., 46, 139-282, doi: 10.1080/00018739700101498. [Link]

Larsen, S., R. Reilinger, H. Neugebauer, and W. Strange, 1992: Global Positioning System measurements of deformations associated with the 1987 Superstition Hills earthquake: Evidence for conjugate faulting. J. Geophys. Res., 97, 4885-4902, doi: 10.1029/92JB00128. [Link]

Lee, H. K. and H. P. Schwarcz, 1995: Fractal clustering of fault activity in California. Geology, 23, 377-380, doi: 10.1130/0091-7613(1995)023<0377:FCOFAI>2.3.C O;2. [Link]

Lee, Y. T., D. L. Turcotte, J. B. Rundle, and C. C. Chen, 2012: A statistical damage model with implications for precursory seismicity. Acta Geophys., 60, 638-663, doi: 10.2478/s11600-011-0069-2. [Link]

Lin, H. I., 2004: Earthquake source scaling of moderate to large earthquakes in Taiwan: Study of $2003 \mathrm{Mw}>6$ Taiwan earthquakes. Master Thesis, National Central University, Taiwan, 95 pp. (in Chinese)

Liu, H. L. and D. V. Helmberger, 1983: The near-source ground motion of the 6 August 1979 Coyote Lake, California, earthquake. Bull. Seismol. Soc. Am., 73, 201-218.

Ma, K. F. and H. Y. Wu, 2001: Quick slip distribution determination of moderate to large inland earthquakes using near-source strong motion waveforms. Earthq. Eng. Eng. Seismol., 3, 1-10. 
Ma, K. F., J. Mori, S. J. Lee, and S. B. Yu, 2001: Spatial and temporal distribution of slip for the 1999 Chi-Chi, Taiwan, earthquake. Bull. Seismol. Soc. Am., 91, 10691087, doi: 10.1785/0120000728. [Link]

Ma, K. F., H. Tanaka, S. R. Song, C. Y. Wang, J. H. Hung, Y. B. Tsai, J. Mori, Y. F. Song, E. C. Yeh, W. Soh, H. Sone, L. W. Kuo, and H. Y. Wu, 2006: Slip zone and energetics of a large earthquake from the Taiwan Chelungpu-fault Drilling Project. Nature, 444, 473476, doi: 10.1038/nature05253. [Link]

Mai, P. M., 2007: Database of finite-source rupture models. Available at http://www.seismo.ethz.ch/static/srcmod/ Homepage.html.

Mai, P. M. and G. C. Beroza, 2000: Source scaling properties from finite-fault-rupture models. Bull. Seismol. Soc. Am., 90, 604-615, doi: 10.1785/0119990126. [Link]

Mai, P. M. and K. K. S. Thingbaijam, 2014: SRCMOD: An online database of finite-fault rupture models. Seismol. Res. Lett., 85, 1348-1357, doi: 10.1785/0220140077. [Link]

Mandelbrot, B. B., 1983: The Fractal Geometry of Nature/ Revised and Enlarged Edition, W.H. Freeman and Co., New York, 495 pp.

Manighetti, I., M. Campillo, C. Sammis, P. M. Mai, and G. King, 2005: Evidence for self-similar, triangular slip distributions on earthquakes: Implications for earthquake and fault mechanics. J. Geophys. Res., 110, B05302, doi: 10.1029/2004JB003174. [Link]

Manighetti, I., M. Campillo, S. Bouley, and F. Cotton, 2007: Earthquake scaling, fault segmentation, and structural maturity. Earth Planet. Sci. Lett., 253, 429-438, doi: 10.1016/j.eps1.2006.11.004. [Link]

Mendoza, C. and S. H. Hartzell, 1988: Inversion for slip distribution using teleseismic $P$ waveforms: North Palm Springs, Borah Peak, and Michoacan earthquakes. Bull. Seismol. Soc. Am., 78, 1092-1111.

Mendoza, C. and S. H. Hartzell, 1989: Slip distribution of the 19 September 1985 Michoacan, Mexico, earthquake: Near-source and teleseismic constraints. Bull. Seismol. Soc. Am., 79, 655-669.

Murotani, S., H. Miyake, and K. Koketsu, 2008: Scaling of characterized slip models for plate-boundary earthquakes. Earth Planets Space, 60, 987-991, doi: 10.1186/BF03352855. [Link]

Ogata, Y. and K. Abe, 1991: Some statistical features of the long-term variation of the global and regional seismic activity. Int. Stat. Rev., 59, 139-161, doi: 10.2307/1403440. [Link]

Okubo, P. G. and K. Aki, 1987: Fractal geometry in the San Andreas fault system. J. Geophys. Res., 92, 345-355, doi: 10.1029/JB092iB01p00345. [Link]

Ostojic, S., E. Somfai, and B. Nienhuis, 2006: Scale invariance and universality of force networks in static granular matter. Nature, 439, 828-830, doi: 10.1038/ nature 04549. [Link]

Pacheco, J. P., C. H. Scholz, and L. R. Sykes, 1992: Changes in frequency-size relationship from small to large earthquakes. Nature, 355, 71-73, doi: 10.1038/355071a0. [Link]

Papadopoulos, G. A. and V. Dedousis, 1992: Fractal approach of the temporal earthquake distribution in the Hellenic arc-trench system. Pure Appl. Geophys., 139, 269-276, doi: 10.1007/BF00876331. [Link]

Power, W. L., T. E. Tullis, S. R. Brown, G. N. Boitnott, and C. H. Scholz, 1987: Roughness of natural fault surfaces. Geophys. Res. Lett., 14, 29-32, doi: 10.1029/ GL014i001p00029. [Link]

Rundle, J. B., 1989: Derivation of the complete GutenbergRichter magnitude-frequency relation using the principle of scale invariance. J. Geophys. Res., 94, 1233712342, doi: 10.1029/JB094iB09p12337. [Link]

Sekiguchi, H., K. Irikura, T. Iwata, Y. Kakehi, and M. Hoshiba, 1996: Determination of the location of faulting beneath Kobe during the 1995 Hyogo-ken Nanbu, Japan, earthquake from near-source particle motion. Geophys.Res.Lett., 23, 387-390, doi: 10.1029/96GL00251. [Link]

Shaw, B.E. and S. G. Wesnousky, 2008: Slip-length scaling in large earthquakes: The role of deep-penetrating slip below the seismogenic layer. Bull. Seismol. Soc. Am., 98, 1633-1641, doi: 10.1785/0120070191. [Link]

Shimazaki, K., 1986: Small and large earthquakes: The effects of the thickness of seismogenic layer and the free surface. In: Das, S., J. Boatwright, and C. H. Scholz (Eds.), Earthquake Source Mechanics, American Geophysical Union, Washington, D. C., 209-216, doi: 10.1029/GM037p0209. [Link]

Shin, T. C. and J. S. Chang, 2005: Earthquake monitoring systems in Taiwan. In: Wang, J. H. (Ed.), The 921 ChiChi Major Earthquake, Office of Inter-Ministry S\&T Program for Earthquake and Active-fault Research, NSC, 43-59. (in Chinese)

Somerville, P., K. Irikura, R. Graves, S. Sawada, D. Wald, N. Abrahamson, Y. Iwasaki, T. Kagawa, N. Smith, and A. Kowada, 1999: Characterizing crustal earthquake slip models for the prediction of strong ground motion. Seismol. Res. Lett., 70, 59-80, doi: 10.1785/ gssrl.70.1.59. [Link]

Sornette, D., 1998: Discrete-scale invariance and complex dimensions. Phys. Rep., 297, 239-270, doi: 10.1016/ S0370-1573(97)00076-8. [Link]

Steidl, J. H., R. J. Archuleta, and S. H. Hartzell, 1991: Rupture history of the 1989 Loma Prieta, California, earthquake. Bull. Seismol. Soc. Am., 81, 1573-1602.

Turcotte, D. L., 1989: Fractals in geology and geophysics. Pure Appl. Geophys., 131, 171-196. doi: 10.1007/ BF00874486. [Link]

Turcotte, D. L., 1997: Fractals and Chaos in Geology and 
Geophysics, Cambridge University Press, 416 pp.

Wald, D. J., 1992: Strong motion and broadband teleseismic analysis of the 1991 Sierra Madre, California, earthquake. J. Geophys. Res., 97, 11033-11046, doi: 10.1029/92JB00565. [Link]

Wald, D. J., 1996: Slip history of the 1995 Kobe, Japan, earthquake determined from strong motion, teleseismic, and geodetic data. J. Phys. Earth, 44, 489-503, doi: 10.4294/jpe1952.44.489. [Link]

Wald, D. J. and T. H. Heaton, 1994: Spatial and temporal distribution of slip for the 1992 Landers, California, earthquake. Bull. Seismol. Soc. Am., 84, 668-691.

Wald, D. J. and P. G. Somerville, 1995: Variable-slip rupture model of the great 1923 Kanto, Japan, earthquake: Geodetic and body-waveform analysis. Bull. Seismol. Soc. Am., 85, 159-177.

Wald, D. J., D. V. Helmberger, and S. H. Hartzell, 1990: Rupture process of the 1987 Superstition Hills earthquake from the inversion of strong-motion data. Bull. Seismol. Soc. Am., 80, 1079-1098.

Wald, D. J., D. V. Helmberger, and T. H. Heaton, 1991: Rupture model of the 1989 Loma Prieta earthquake from the inversion of strong-motion and broadband teleseismic data. Bull. Seismol. Soc. Am., 81, 1540-1572.

Wald, D. J., T. H. Heaton, and K. W. Hudnut, 1996: The slip history of the 1994 Northridge, California, earthquake determined from strong-motion, teleseismic, GPS, and leveling data. Bull. Seismol. Soc. Am., 86, S49-S70.

Wang, J. H., 1996: Multifractal measures of time series of Ms $\geq 7$ earthquakes in Taiwan. J. Geol. Soc. China, 39, 117-123.

Wang, J. H., 1997: On the frequency distribution of rupture lengths of earthquakes synthesized from a one-dimensional dynamical lattice model. J. Phys. Earth, 45, 363-381, doi: 10.4294/jpe1952.45.363. [Link]

Wang, J. H. and C. W. Lee, 1997: Multifractal measures of time series of earthquakes. J. Phys. Earth, 45, 331-345, doi: 10.4294/jpe1952.45.331. [Link]
Wang, J. H. and S. S. Ou, 1998: On scaling of earthquake faults. Bull. Seism. Soc. Am., 88, 758-766.

Wang, J. H., K. C. Chen, W. G. Huang, K. H. Chang, J. C. Wang, and P. L. Leu, 2014: Multifractal measures of $\mathrm{M} \geq 3$ shallow earthquakes in the Taipei metropolitan area. Terr. Atmos. Ocean.Sci., 25, 17-26, doi: 10.3319/ TAO.2013.09.09.01(T). [Link]

Wen, Y. Y., K. F. Ma, T. R. A. Song, and W. D. Mooney, 2009: Validation of the rupture properties of the 2001 Kunlun, China $\left(M_{\mathrm{s}}=8.1\right)$, earthquake from seismological and geological observations. Geophys. J. Int., 177, 555570, doi: 10.1111/j.1365-246X.2008.04063.x. [Link]

Wesnousky, S. G., 2008: Displacement and geometrical characteristics of earthquake surface ruptures: Issues and implications for seismic-hazard analysis and the process of earthquake rupture. Bull. Seismol. Soc. Am., 98, 1609-1632, doi: 10.1785/0120070111. [Link]

Wu, Y. H., C. C. Chen, D. L. Turcotte, and J. B. Rundle, 2013: Quantifying the seismicity on Taiwan. Geophys. J. Int., 194, 465-469, doi: 10.1093/gji/ggt101. [Link]

Yen, Y. T., 2002: Slip distribution of $\mathrm{Mw} \geq 6.0$ aftershocks of the 1999 Chi-Chi Taiwan earthquake. Mater Thesis, National Central University, Taiwan, 122 pp. (in Chinese)

Yen, Y. T. and K. F. Ma, 2011: Source-scaling relationship for $M$ 4.6-8.9 earthquakes, specifically for earthquakes in the collision zone of Taiwan. Bull. Seismol. Soc. Am., 101, 464-481, doi: 10.1785/0120100046. [Link]

Yen, Y. T., K. F. Ma, and Y. Y. Wen, 2008: Slip partition of the 26 December 2006 Pingtung, Taiwan (M 6.9, M 6.8) earthquake doublet determined from teleseismic waveforms. Terr. Atmos. Ocean. Sci., 19, 567-578, doi: 10.3319/TAO.2008.19.6.567(PT). [Link]

Yoshida, S., K. Koketsu, B. Shibazaki, T. Sagiya, T. Kato, and Y. Yoshida, 1996: Joint inversion of near- and farfield waveforms and geodetic data for the rupture process of the 1995 Kobe Earthquake. J. Phys. Earth, 44, 437-454, doi: 10.4294/jpe1952.44.437. [Link] 